\title{
The residual efficacy of a cypermethrin pour-on formulation applied on goats on the mortality and blood intake of Triatoma infestans
}

\author{
Ivana Amelotti/ ${ }^{+}$, Silvia Susana Catalá, David Eladio Gorla \\ Centro Regional de Investigaciones Científicas y Transferencia Tecnológica de La Rioja, Anillaco, La Rioja, Argentina
}

\begin{abstract}
Triatoma infestans is the main vector of Trypanosoma cruzi, the aetiological agent of Chagas disease in the Gran Chaco region of South America. As a frequent blood meal source for triatomine bugs, domestic goats play a key role in the eco-epidemiology of Chagas disease. The aim of this study was to evaluate the mortality and blood intake of $\mathrm{T}$. infestans fed on goats that had been treated with different doses of pour-on insecticide. Third-instar nymphs were fed on goats that had been treated with $0 \mathrm{cc}, 5 \mathrm{cc}, 10 \mathrm{cc}$ or $15 \mathrm{cc}$ of a pour-on formulation of cypermethrin. The exposure of $\mathrm{T}$. infestans to animals treated at different post-application intervals revealed a residual activity of the insecticide. The mortality rate in the treated groups was higher than in the control groups until 30 days postinsecticide application $(p=0.03)$, except in the group treated with $5 c c$, in which no mortality was detected after seven days of insecticide application. Rainfall affected the triatomicide effect, reducing the time of residual activity. The cypermethrin pour-on treatment decreased the blood intake of $\mathrm{T}$. infestans. Thirty days after the cypermethrin application, nymph mortality was $16 \%( \pm 13)$ with both doses $(10 \mathrm{cc}$ and $15 \mathrm{cc})$. The $15 \mathrm{cc}$ dose did not result in higher insect mortality or increased persistence compared to the $10 \mathrm{cc}$ dose.
\end{abstract}

Key words: Triatoma infestans - cypermethrin - pour-on - Chagas disease - vector control

Domestic goats (Capra hircus), much like other domestic vertebrates, are important feeding sources for Triatoma infestans, the main vector of Trypanosoma cruzi. Chagas disease, caused by T. cruzi, affects the rural households of the Gran Chaco region of South America. T. infestans has been the target of a regional elimination program known as the Southern Cone Initiative (Schofield \& Kabayo 2008). This program has been successful in Brazil, Chile, Uruguay and parts of Argentina, Bolivia and Paraguay. However, it has not yet succeeded in the Gran Chaco region, an area that is historically endemic for Chagas disease due to the persistence of the triatomine vector (Schofield et al. 2006, Hotez et al. 2008). The epidemiology of Chagas disease in the Gran Chaco region is complex and environmental, socioeconomic and political factors contribute to the persistence of $T$. cruzi transmission (Gürtler et al. 2007, Gorla et al. 2010). It is believed that the persistence of T. infestans in the Gran Chaco region is due to the difficulty in eliminating the vector from peridomestic structures (Gürtler et al. 2007). The structure of the rural houses not only prevents good penetration of the insecticide, but also exposes the chemical to climatic factors that accelerate its degradation (Gürtler et al. 2004). The rural communities in the area have a subsistence economy that is based on domestic animals (predominantly goats, cows and chickens) and the exploitation of wild fauna (Miller 2001, Karlin et al. 2004). Goat breeding is one of the most

Financial support: CONICET, PICT 2006-878 (ANPCYT)

+Corresponding author: iamelotti@crilar-conicet.gob.ar

Received 13 June 2012

Accepted 4 September 2012 important activities, particularly in arid areas, because of the adaptability of goats to scarce water and poor pastures (Vivanco 1986). The pyrethroid insecticides have shown poor triatomicide effects within peridomestic structures and $T$. infestans populations frequently persist (Cecere et al. 1997, Gürtler et al. 2004, Porcasi et al. 2007). Goat corrals typically have complex structures involving interlaced sticks or tree branches as walls, making it very difficult to apply the insecticide by traditional spraying. The poorly treated habitats would subsequently serve as sources of dispersing insects (Cecere et al. 2004, Abrahan et al. 2011). Because of the low efficacy of the current control tools, additional efforts are needed to evaluate and explore new methods of controlling $T$. infestans. Pour-on insecticide formulations are successful control techniques for ectoparasites of cows (Guglielmone et al. 2003) and sheep (Bayvel et al. 1981, Mc Quillán et al. 1983, Levot 1995) as well as goat lice [Damalinia (Bovicola) caprae] (Rossanigo 2003). The aim of the present study was to evaluate the mortality and blood intake of T. infestans fed on goat kids that had been treated with various doses of commercially available cypermethrin pour-on formulations.

\section{MATERIALS AND METHODS}

Two assays were carried out, the first trial was on February 2010 and the second between January-March 2011. A weather station (Weather Monitor II, Davis Instruments, Baltimore, MD) monitored the temperature and rainfall at half-hour intervals throughout the study period.

Female goats between one-two months of age were used because the kids' refuge is commonly associated with a high density of triatomines. The kids were fed a diet of milk and corn. Male goats were not used in this study because they are often sold when they are six weeks of age. The goats used in this study belonged to a 


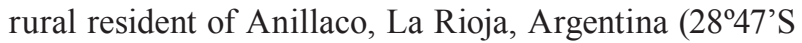
$66^{\circ} 57^{\prime} \mathrm{W}$ ). The goats' owner consented to the use of the animals after receiving a complete explanation of the intended study. The kids were kept in a corral that included a roofed area and the owner maintained his normal caretaking routine throughout the study period. The goats' weight was measured before and after the completion of the trial as an indication of their health. Their average initial weight was $10 \mathrm{~kg} \pm 1$. Goats were randomly assigned to treatment groups that each received different insecticide doses. Each goat received a unique identification tag to guarantee its association with the same experimental group throughout the study. The goats included in the study did not leave the corral during the trial.

The cypermethrin (RS)-y-cyano-3-phenoxybenzyl (1RS)-cis, trans-3-(2,2-dichlorovinyl)-2,2-methylcyclopropanecarboxylate was formulated as a pour-on solution with $6 \%$ active ingredient (a.i.) by Biogenesis SA (Buenos Aires, Argentina) and commercialised as Aciendel. The formulation is registered in Argentina for veterinary use and meat consumption by humans is considered safe if animals have not received the formulation during the previous six days.

In the first trial, four cypermethrin doses were evaluated: $0 \mathrm{cc}, 5 \mathrm{cc}, 10 \mathrm{cc}$ and $15 \mathrm{cc}$ per animal. Five goats were used in each experimental group ( 20 goats). In the second trial, three cypermethrin doses were evaluated: 0 $\mathrm{cc}, 10 \mathrm{cc}$ and $15 \mathrm{cc}$ per animal. Three goats were included in the control group $(0 \mathrm{cc})$ and 5 goats in each treated group (13 goats). The pour-on insecticide was applied to the goats in the treated groups with a needleless syringe. Half of the insecticide was applied to the middle back of the goat and the remainder was applied to the abdomen. The control group goats were similarly handled, but did not receive the insecticide.

The insects used in this study were third-instar $T$. infestans nymphs and were provided by the breeding facility of the National Coordination for Vector Control (Punilla, Córdoba). These insects were bred under controlled conditions and were fed on chickens (Gallus sp.). The third-instar nymphs used in the experiments were 15 days post-moulting and unfed. They were kept under controlled temperature $\left(26-28^{\circ} \mathrm{C}\right)$ and humidity $(50-70 \%$ relative humidity) and were housed in appropriately labelled plastic jars.

To measure the effect of the insecticide, groups of 30 third-instar nymphs of T. infestans were fed on each goat per feeding interval (divided into 3 subsamples of 10 nymphs). T. infestans nymphs were allowed to feed for $15 \mathrm{~min}$. The goats were immobilised and the nymphs were placed over the goats' abdomens (where the insecticide was applied). During the feeding process, the nymphs walked over a nylon mesh that was in partial contact with the goats' skin.

The residual effect of the insecticide was measured using independent groups of nymphs fed at one, 15, 30 and 45 days following the insecticide application (or until there was no longer a detectable effect of the insecticide on the nymphs). Only the group of goats treated with $5 \mathrm{cc}$ included a feeding time point at seven days post-cypermethrin application.
After feeding, the nymphs were taken to the laboratory for mortality and blood intake measurements. The insects were kept in appropriately labelled plastic jars under the above-mentioned controlled conditions. The blood intake was calculated as the difference between individual jar weights immediately before and after each feeding divided by the number of living nymphs per jar. The nymphs were weighed as a group and not individually, to avoid excessive manipulation that could artificially increase the mortality rate.

The insects were considered dead when they were motionless after 14 days of contacting a treated goat, as Alzogaray and Zerba (1997) showed that individuals that received a sub-lethal pyrethroid dose could be knocked down, but could recover after 14 days.

The data were analysed using parametric analysis of variance when variance heterogeneity was rejected (Levene test). Cases with heterogeneous variances were analysed with the Kruskal-Wallis test. All statistical calculations were carried out with Infostat 2011 (Grupo InfoStat, FCA, National University of Córdoba, Argentina).

\section{RESULTS}

No differences in weight increase $(2.5 \mathrm{~kg} \pm 1)$ were found among the kids exposed to different treatments ( $p$ $>0.05$ ). During the 15 days of the first trial, the average ambient temperature ranged from $15-27^{\circ} \mathrm{C}$. It rained immediately after the insecticide application and the accumulated rainfall during the 15 days of the first trial was $21 \mathrm{~mm}$. During the 45 days of the second trial study period, the average temperature ranged from $16-25.3^{\circ} \mathrm{C}$. It did not rain immediately following the insecticide application, but 15 days after the application there were rains of varying intensity $(1-10 \mathrm{~mm})$. For the duration of the assay (45 days), the total rainfall was $79 \mathrm{~mm}$ (Fig. 1).

Mortality - first trial - The nymphs fed on goats treated $24 \mathrm{~h}$ before with $10 \mathrm{cc}$ and $15 \mathrm{cc}$ of the insecticide formulation showed a mortality of $>90 \%$. The nymphs that were exposed to the $5 \mathrm{cc}$ dose showed higher mortality than the control group, but lower mortality than the groups treated with the highest dose. After seven days of insecticide application, nymphs that were exposed to goats that had received the $5 \mathrm{cc}$ dose showed higher mortality than their corresponding control group ( $32 \% \pm 30$ vs. $0 \%)$. The triatomicide effect decreased in the later post-application time points for all the tested doses. The last feeding was performed 15 days after the insecticide application and mortality in the treated groups (all doses) did not differ from the control group at this time point (Fig. 2).

Second trial - Because the $5 \mathrm{cc}$ dose showed the lowest triatomicide effect in the first trial, the experimental group treated with $5 \mathrm{cc}$ of pour-on cypermethrin was withdrawn from the second trial. The mortality of the nymphs that fed on treated goats was higher than the nymphs that fed on control goats until 30 days after the insecticide application $(p=0.03)$. After 45 days, there was no difference between the mortality rates of the control and treated groups $(\mathrm{p}>0.05)$ (Fig. 3).

Blood intake estimation - first trial - There was no difference in the blood intake among the nymphs ex- 
posed to different doses of cypermethrin $(\mathrm{p}>0.05)$ and the amount of blood did not exceed $13.8 \mathrm{mg}$ per nymph in any of the evaluated post-application time points. On average, the blood intake by groups of nymphs that were exposed to untreated goats $(17.7 \pm 11.3 \mathrm{mg})$ was higher than the blood intake by nymphs that were exposed to all treated goats $(\mathrm{p}<0.01)$. None of the nymphs (neither experimental nor control groups) moulted to the fourth instar during the study period.

Second trial - The blood intake data from this trial are shown in Table. In most of the dates, the blood intake of the nymphs that fed on treated goats was lower than the blood intake of nymphs that were exposed to the control group $(\mathrm{p}<0.05)$. The nymphs that fed 45 days after the $10 \mathrm{cc}$ insecticide application dose showed a moulting rate of $10 \%( \pm 9)$, whereas in the control group the moulting rate was $14 \%( \pm 9)(p>0.05)$.

\section{DISCUSSION}

This study evaluated the effect of exposing goats to pour-on cypermethrin ( $6 \%$ a.i.) on third-instar nymphs of $T$. infestans under natural conditions. There was a high mortality $(>90 \%)$ of nymphs that were exposed to goats that had been treated with $10 \mathrm{cc}$ or $15 \mathrm{cc}$ of insecticide $24 \mathrm{~h}$ before. The persistence of the insecticide was strongly affected by the rain that occurred during the experimental period. When rainfall was absent during the days immediately following the application of the insecticide (Fig. 1), the nymphs that were exposed to treated goats showed higher mortality than the control group until 30 days post-insecticide application. The mortality recorded a month after the pour-on application was $16 \%$ (for doses of $10 \mathrm{cc}$ and $15 \mathrm{cc}$ ).

A

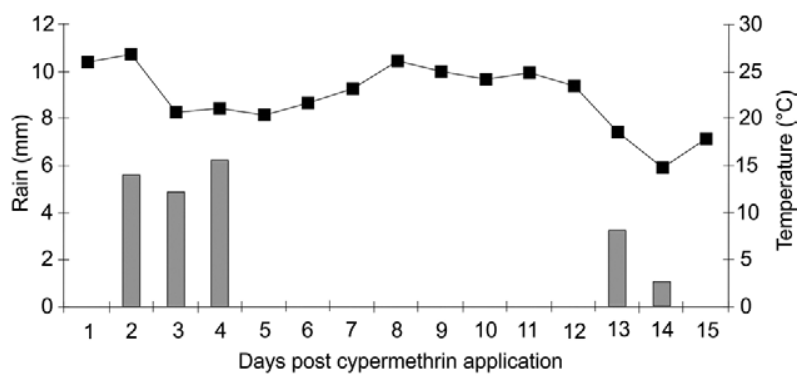

B

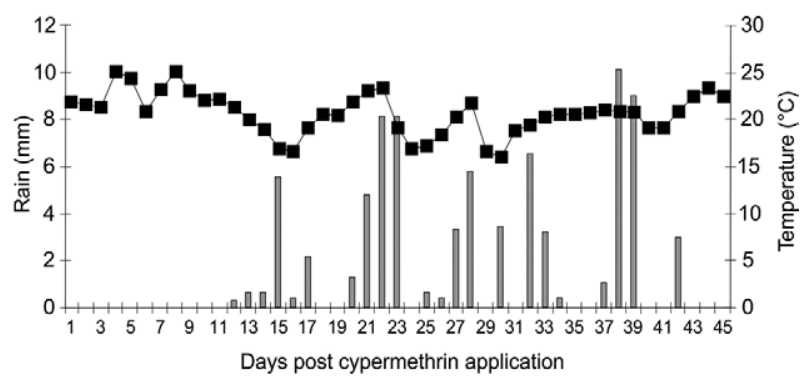

Fig. 1: weather conditions during the study period. A: first trial, during February 2010; B: second trial, between January 5 2011-March 12 2011; black squares: average temperatures $\left({ }^{\circ} \mathrm{C}\right)$; verticals bars: rainfall $(\mathrm{mm})$.
This experiment showed that the highest insecticide dose of $15 \mathrm{cc}$ did not result in higher mortality than the $10 \mathrm{cc}$ dose, suggesting that the lower dose is preferable when using this method in the field. The $5 \mathrm{cc}$ dose showed an insecticidal effect until seven days after the pour-on application and, therefore, provided too short a window to be useful as a triatomicide.

The application protocol allowed for good coverage of thin and warm-skinned body areas, which may be more likely to attract $T$. infestans, due to a combination of insecticide doses and the small likely to attract $T$. infestans. When applied on laboratory chickens, the same pour-on cypermethrin formulation resulted in mortality rates of $T$.

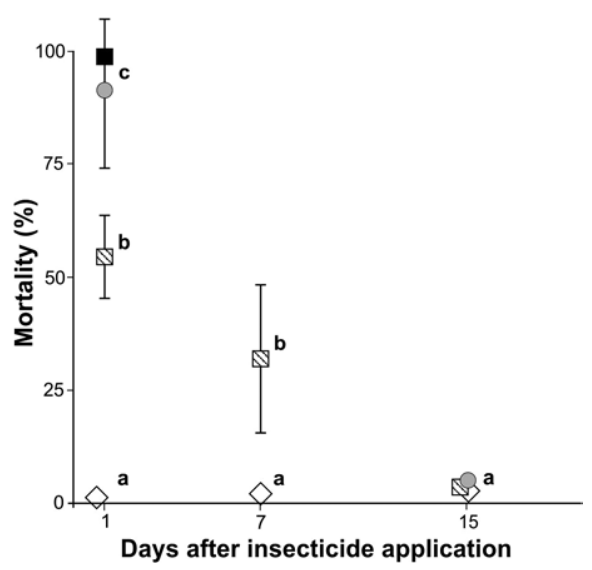

Fig. 2: mortality (\%) of independent groups of third instar nymphs of Triatoma infestans fed on goats treated with different doses of cypermethrin pour-on at different intervals after the insecticide application (first trial). Black squares: $15 \mathrm{cc}$; diagonal squares: $5 \mathrm{cc}$; grey circles: $10 \mathrm{cc}$; white diamonds: control $(0 \mathrm{cc})$. Different letters indicate groups differing significantly in the same date at $\mathrm{p}<0.05$. Verticals lines are standard deviations.

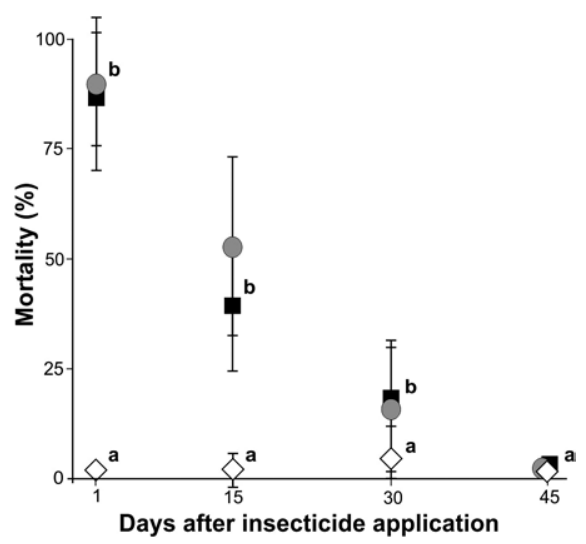

Fig. 3: mortality (\%) of independent groups of third instar nymphs of Triatoma infestans fed on goats treated with different doses of cypermethrin pour-on at different intervals after the insecticide application (second trial). Black squares: $15 \mathrm{cc}$; grey circles: $10 \mathrm{cc}$; white diamonds: control $(0 \mathrm{cc})$. Different letters indicate groups differing significantly in the same date at $\mathrm{p}<0.05$. Verticals lines are standard deviations. 
infestans nymphs above $77 \%$ until 45 days after the application (Amelotti et al. 2010). The loss of residual activity of the cypermethrin pour-on was faster in goats than in chickens under field conditions, most likely because the hen feathers act to insulate the insecticide. The belly of the goat is a bare area and constantly experiences friction with the ground. Therefore, when applied to the belly, the insecticide likely undergoes degradation and rainwater exposure can more readily wash it away. Although some of the insecticide was placed on the dorsal midline, the concentration at which it was applied was most likely too low to trigger a triatomicide effect far from the application point (Amelotti et al. 2009, 2010).

The blood intake volume was lower in the nymphs that were exposed to treated goats, perhaps because cypermethrin has an inhibitory effect on feeding. According to Picollo et al. (1993) and Alzogaray et al. (2000), there are repellent components that inhibit the feeding of $T$. infestans. A lower blood intake leads to a lower nutritional status, which may, in turn, delay nymphal development and decrease adult fertility (Giojalas \& Montenegro 1986, Catalá de Montenegro 1989).

A potential limitation of the present study is that the reported data are restricted to the third nymphal stage of $T$. infestans. It is known that third-instar nymphs are more susceptible to insecticides than other life stages and that fifth instar nymphs have the best detoxifying mechanism to degrade insecticides (Wood et al. 1993, Alzogaray \& Zerba 2001). Thus, other results might have been obtained if this study had utilised fourth or fifthinstar nymphs. Another potential limitation of the experimental design is that the nymphs were forced to feed precisely where the insecticide was applied. The dispersion rate of the insecticide through the treated skin is very low; as such, significant variability in nymph mortality may occur depending on how far the feeding site is from the site of the insecticide application (Amelotti et al. 2012). The results of this report should be considered to be the highest attainable effect of the insecticide on the mortality of $T$. infestans.

\section{TABLE}

Blood intake (mg) by third instar nymphs of Triatoma infestans fed on goats at different intervals after the pour-on cypermethrin application

\begin{tabular}{lccc}
\hline & \multicolumn{3}{c}{ Experimental groups } \\
\cline { 2 - 4 } $\begin{array}{l}\text { Days after } \\
\text { insecticide } \\
\text { application }\end{array}$ & $\begin{array}{c}\text { Control } \\
\text { (average } \pm \mathrm{SD} \text { ) }\end{array}$ & $\begin{array}{c}10 \mathrm{cc} \\
\text { (average } \pm \mathrm{SD} \text { ) }\end{array}$ & $\begin{array}{c}15 \mathrm{cc} \\
\text { (average } \pm \mathrm{SD} \text { ) }\end{array}$ \\
\hline 1 & $2.5 \pm 2^{a}$ & $0.4 \pm 0.8^{b}$ & $1.1 \pm 1.3^{b}$ \\
15 & $4.2 \pm 5.2^{a}$ & $0.7 \pm 0.8^{b}$ & $0.8 \pm 5.2^{b}$ \\
30 & $3.4 \pm 2.6^{a}$ & $2 \pm 2.4^{a}$ & $1.9 \pm 3.3^{a}$ \\
45 & $7.5 \pm 6.8^{a}$ & $4.9 \pm 3.8^{a, b}$ & $1.5 \pm 3.1^{b}$ \\
\hline
\end{tabular}

numbers are averages of groups of $30 \mathrm{~T}$. infestans nymphs. Same letters denote homogeneous groups within the same date, $p>0.05$, Kruskal Wallis. SD: standard deviation.
The results of the present study suggest that the complete replacement of triatomine control with this treatment alone will not solve the problem of $T$. infestans.

To achieve the greatest possible impact, the use of a vector control method should be accompanied by an adequate knowledge of the population dynamics of the insect to be controlled. The time of the year most suitable for spraying $T$. infestans populations with insecticides is the beginning of the cold season, coinciding with the insects' lowest reproduction rate (Gorla 1991). For the use of pour-on cypermethrin on goats that live in a strongly seasonal environment, results may be considerably improved if the insecticide is administered in two consecutive applications every 30 days at the beginning of the warm season, when the insects exit their winter phase and need to ingest blood quickly. Under these conditions, it is likely that the effect of the pour-on treatment will be stronger than what was measured experimentally. It is crucial to rapidly eliminate the insects as they come out of their winter phase, as that is when they are more likely to take a large blood meal, thereby increasing the risk of T. cruzi transmission (Trumper \& Gorla 1991, Catalá 1994). Conversely, applying the pour-on treatment in the winter is not advisable because $T$. infestans decreases its metabolism, lowers its food intake and can fast for long periods of time at low temperatures (Catalá 1991).

Pour-on insecticides do not have the necessary residual requirements to be an exclusive vector control method. However, when used in conjunction with the traditional spraying technique, this formulation may significantly increase triatomine mortality, thus increasing the efficacy of $T$. infestans control in highly infested peridomestic environments.

\section{ACKNOWLEDGEMENTS}

To R Stariolo (Vectors Reference Center, National Coordination for Vector Control), for the insect provision, to L Fiorelli, for the design of Figs, to N Folguera, J Paliza, L Hernández, M Garlatti and L Abrahan, for lab and general support, to Anillaco's families, for participating in the study, and to R Gonzalez Llanos, for the insecticide provision.

\section{REFERENCES}

Abrahan LB, Gorla DE, Catalá SS 2011. Dispersal of Triatoma infestans and other Triatominae species in the arid Chaco of Argentina - Flying, walking or passive carriage? The importance of walking females. Mem Inst Oswaldo Cruz 106: 232-239.

Alzogaray RA, Fontan A, Zerba EN 2000. Repellency of deet to nymphs of Triatoma infestans. Med Vet Entomol 14: 6-10.

Alzogaray RA, Zerba EN 1997. Incoordination, paralysis and recovery after pyrethroid treatment on nymphs III of Triatoma infestans (Hemiptera: Reduviidae). Mem Inst Oswaldo Cruz 92: 431-435.

Alzogaray RA, Zerba EN 2001. Behavioral response of fifth instar nymphs of Triatoma infestans (Hemiptera: Reduviidae) to pyrethroids. Acta Trop 78: 51-57.

Amelotti I, Catalá SS, Gorla DE 2009. Response of Triatoma infestans to pour-on cypermethrin applied to chickens under laboratory conditions. Mem Inst Oswaldo Cruz 104: 481-485.

Amelotti I, Catalá SS, Gorla DE 2010. The effects of cypermethrin pour-on and piperonyl butoxide on Triatoma infestans under laboratory conditions. J Med Entomol 47: 1135-1140. 
Amelotti I, Catalá SS, Gorla DE 2012. Effects of fipronil on dogs over Triatoma infestans, the main vector of Trypanosoma cruzi, causative agent of Chagas disease. Parasitol Res 111: 1457-1462.

Bayvel ACD, Kieran PJ, Townsend RB 1981. Technical details of a new treatment for external parasites in sheep. Wool Tech Sheep Breed 29: 17-24.

Catalá de Montenegro SS 1989. Relaciones entre consumo de sangre y ovogenesis en Triatoma infestans Klug, 1834 (Hemiptera-Reduviidae). Chagas 5: 3-10.

Catalá SS 1991. The biting rate of Triatoma infestans in Argentina. Med Vet Entomol 5: 325-333.

Catalá SS 1994. Bloodmeal size and nutritional status of Triatoma infestans under natural climatic conditions. Med Vet Entomol 8: 104-106.

Cecere MC, Gürtler RE, Canale D, Chuit R, Cohen JE 1997. The role of peridomiciliary area in the elimination of Triatoma infestans from rural Argentine communities. Rev Panam Salud Publica 1: 273-279.

Cecere MC, Vazquez-Prokopec GM, Gürtler RE, Kitron U 2004. Spatiotemporal analysis of reinfestation by Triatoma infestans (Hemiptera: Reduviidae) following insecticide spraying in a rural community in north-western Argentina. Am J Trop Med Hyg 71: $803-810$

Giojalas LC, Montenegro SC 1986. Efecto del ayuno sobre la eficiencia reproductiva en machos de Triatoma infestans (Klug, 1834). Physis 44: 55-62.

Gorla DE, Ponce C, Dujardin JP, Schofield CJ 2010. Control strategies against Triatominae. In J Telleria, M Tibayrenc, American trypanosomiasis Chagas disease one hundred years of research, Elsevier, Madrid, p. 233-245.

Gorla DE 1991. Recovery of Triatoma infestans populations after insecticide application: an experimental field study. Med Vet Entomol 5: 311-324.

Guglielmone AA, Volpogni MM, Anziani OS, Castelli ME, Mangold AJ 2003. Control de Haematobia irritans con un tópico de insecticidas organofosforados en baja concentración, suspendidos en un vehículo de alta densidad. Rev FAVE 2: 29-33.

Gürtler RE, Canale DM, Spillmann C, Satariolo R, Salomon OD, Blanco S, Segura EL 2004. Effectiveness of residual spraying of peridomestic ecotopes with deltametrin and permetrin on Triatoma infestans in rural western Argentina: a district-wide randomized trial. Bull World Health Organ 82: 196-205.
Gürtler RE, Kitron U, Cecere MC, Segura EL, Cohen JE 2007. Sustainable vector control and management of Chagas disease in the Gran Chaco, Argentina. Proc Natl Acad Sci USA 104: 16194-16199.

Hotez PJ, Bottazzi ME, Franco-Paredes C, Ault SK, Periago MR 2008. The neglected tropical diseases of Latin America and the Caribbean: a review of disease burden and distribution and a roadmap for control and elimination. PLoS Negl Trop Dis 2: e300.

Karlin U, Catalán L, Coirini R, Zapata R 2004. Uso y manejo sustentable de los bosques nativos del Chaco Arido. In MF Arturi, JL Frangi, JF Goya, Ecología y manejo de bosques nativos de Argentina. Presentación multimedia, Editorial Universidad Nacional de La Plata, La Plata, p. 1-22.

Levot GW 1995. In vivo synergism of cypermethrin by piperonyl butoxide in Bovicola ovis (L.) (Phthiraptera: Trichodectidae). Aust J Entomol 34: 299-302.

MacQuillan MJ, Northam A, Amery MI 1983. Effectiveness against sheep body louse and itch mite of a cypermethrin formulation. Wool Tech Sheep Breed 31: 99.

Miller E 2001. Peoples of the Gran Chaco, Greenwood Publishing Group Ed, Portsmouth, 182 pp.

Picollo MI, Seccacini E, Vassena C, Zerba EN 1993. Feeding and mating deterrency by sulfhydryl reagents in Triatoma infestans. Acta Trop 52: 297-307.

Porcasi X, Hrellac H, Catalá S, Moreno M, Abrahan L, Hernandez L, Gorla DE 2007. Infestation of rural houses by Triatoma infestans in the region of Los Llanos (La Rioja, Argentina). Mem Inst Oswaldo Cruz 102: 63-68.

Rossanigo CE 2003. Actualización sobre las parasitosis del ganado caprino. Vet Arg 20: 188-204.

Schofield CJ, Jannin J, Salvatella R 2006. The future of Chagas disease control. Trends Parasitol 22: 583-588.

Schofield CJ, Kabayo JP 2008. Trypanosomiasis vector control in Africa and Latin America. Parasit Vectors 1: 24.

Trumper EV, Gorla DE 1991. Density dependent timing of defaecation by Triatoma infestans. Trans Roy Soc Trop Med Hyg 85: 800-802.

Vivanco HW 1986. Recent developments in reproductive techniques of sheep and goats. In VM Timon, JP Hanrahan, Small ruminant production in the developing countries, FAO, Rome, p. 31-51.

Wood E, Picollo MI, Zerba E 1993. Comparación entre la variación de la capacidad detoxificante y la diferente susceptibilidad al insecticida malation entre ninfas $\mathrm{V}$ de distinta edad de Triatoma infestans. An Asoc Quim Argentina 81: 153-162. 